\title{
A COMPREHENSIVE SCHEME FOR THE QUALITY CONTROL OF DRUGS AND MEDICATED PRODUCTS
}

$\mathrm{T}$ HE following scheme for the quality control of drugs and medicated products was drawn up by a technical committee of the Pharmaceutical Society of Great Britain and deals with, in its widest aspects, the testing of drugs from the stage of their importation or manufacture to the delivery of the dispensed medicine to the patient. The report has been submitted by the Society to the Ministry of Health.

As a consequence of its earlier consideration of various aspects of quality control applicable to drugs and medicated products, the Science Committee (Pharma ceutical Analysis) of the Pharmaceutical Society of Great Britain was requested in June 1963 to prepare a model drug-testing scheme to be operated in the United Kingdom. It seemed expedient and proper to consider a moro comprehonsive scheme than those now operating to ensure that all drugs supplied to the public, in whatever manner, should be controlled.

In addition to the sampling and testing of drugs (a necessary process in any system of quality control) provision is planned for inspecting, licensing and registering premises in which drugs are manufactured, compounded or stored. A proposal for controlling imported drugs is also included. To make such control effective, the Committee envisages the establishment of a Directorate having the necessary legal powers with inspection and with laboratory facilities. (Detailed considerations of the legislation required and of the financing of the project were considered to be outside the terms of reference of the Committee.)

In presenting its proposals, the Committee realizes that expediency may require these proposals to be modified for an interim period during which, for example, it may be necessary to correlate them with existing legislation and to use some of the existing machinery for testing drugs. Nevertheless, this period should be strictly limited and no modification should violate the basic principle that all drugs supplied to the public should be subject to scrutiny.

\section{REGISTRATION AND LICENSING}

The bodies over which some degree of control will need to be exercised include: drug manufacturers; medicated product manufacturers; importers of drugs both in bulk and as formulated products; drug wholesalers; hospital manufacturing and dispensing units; medical, pharmaceutical, dental and veterinary practitioners who earry out dispensing; clinics, and all retailers handling drugs. The purpose of registration and licensing is to ensure, so far as is reasonable, that any premises used for the manufacture, warehousing or distribution of drugs are satisfactory. The issue of a licence to manufacture, import or distribute will depend on the acceptance of the principle that the accredited representative of the Executive Organization has a right to enter, inspect and take samples. Re-licensing will be necessary following a change of ownership. Since the deterioration of drugs during storage is a major reason for the sale of poor-quality drugs, the adequacy of warehous 9 and other storage facilities requires attention.

\section{Manufacturing Units}

The registration and licensing of premises to be used for the manufacture of drugs in bulk or as formulated products, including medicated toilet preparations, will depend on the general level of hygiene and management. The maintenance of an efficient system of internal control records, open for inspection, relating to the various products is an integral part of a control operation. The existence of a scheme adequate for tracing the origin of any batch of drug or medicinal preparation should be a part of any internal record system.

Premises. These will be subject to inspection or approval before a licence to manufacture drugs is issued. The facilities available and the condition of the premises will determine the decision of the Executive Organization. The issue of a licence will be for a limited period of, say, three years, after which renewal will be necessary. As it is imperative that there be some measure of control of the raw materials, including packaging materials, right of entry to the premises must be allowed to inspectors appointed by the Executive Organization. Such inspectors must also have access to the production records and be given the powers to take any necessary action.

Personnel. The complexity of modern pharmaceutical industry necessitates that effective supervisory responsibility for drug manufacture be taken by highly qualified and experienced personnel. The manufacture of bulk drugs should be controlled by professionally qualified persons, such as chemists, pharmacists or chemical engineers, while the manufacture of medicated products in industry and in hospital practice should bo the responsibility of pharmacists or chemists having appropriate experience. This supervisory staff should be listed by the Executive Organization, who would be informed immediately of any change in personnel. As an interim moasure only, the Committee considers that a list of technicians and other experienced operatives, not qualified in the professional sense, be compiled. Such people may be granted responsibility for supervisory control where it can be shown that they have had the necessary supervisory experience within the industry for a period of not less than five years before the date of the inception of this scheme.

\section{Warehouses and other Storage Units}

Experience in the pharmaceutical industry has shown that there can be a considerable delay between the manufacture of a medicated product and its utilization by members of the public. The instability of certain drugs and the products containing them makes it imperative to have proper conditions of drug storage in order to avoid deterioration.

Bulk drug manufacturing units. The right to inspect storage areas is implicit in the issue of a licence to the drug manufacturing organization, since it is important that the drugs should not be subject to rodent infestation or other contamination, or to extreme moisture and temperature conditions.

Hospital manufacturing units. The quantities of bulk drugs in these units will be relatively small and storage in the pharmacy may be adequate. If it is necessary to store outside the pharmacy the factors under the foregoing "Bulk drug manufacturing units" must be taken into account.

Wholesalers' warehouses. These premises must be subject to the same control as for "Bulk drug manufacturing units". Special attention will have to be directed to the establishment of a satisfactory system designed to prevent 
the accumulation of old material, and to products carrying an expiry date.

Importers' warehouses. Since comprehensive inspection of foreign manufacturers' premises is not, in general, practicable, some control will need to be exercised when the product is landed in the United Kingdom. Warehouses at the docks and airports will require registration and be subject to inspection, etc. Appropriate information on the commodity is required. A separate clearance certificate will be necessary on each occasion. While bonded warehouses into which imported drugs will go pending their clearance will not normally be subject to inspection and registration, it is considered that the full co-operation of the Board of Trade in disclosing such importations will be required and that the storage conditions are suitable. The rejection of unsatisfactory imports at this stage could prevent their transfer to the importers' warehouses.

\section{Outlets to the Consumer}

As the purposo of a comprehensive quality control scheme for drugs is that a pharmaceutically satisfactory product be made available to the public, some inspection control must be exercised at this point of distribution. The distribution points are concerned with the unrestricted purchase of medicated products. Typical examples are pharmacies, drug stores, listed sellers, etc. An important contact point is that which occurs following the presentation of a prescription in either medical, pharmaceutical, dental or veterinary practice.

Sale by retail. The Committee feels some concern at the present situation where it is now possible to purchase drugs and medicated products from stores, grocers, market stalls, licensed premises, etc., where control is exercised by people with little or no knowledge of the problems associated with the drugs. The use of vonding machines inadequately protected from the weather and granting easy access to drugs is to be deplored. It is therefore essential that all premises used for the sale of drugs should be registered and subject to inspection and approval.

Dispensaries. Dispensaries may be in retail shops, doctors' surgeries, hospitals or clinies. All such premises in which prescriptions from members of the medical, dental or veterinary professions are dispensed should be registered and open to inspection by the representatives of the Executive Organization.

\section{SAMPLING AND TESTING}

The object of sampling and testing is to provide an effective check on the quality of drugs being offered to the public as prepacked drugs, formulated products and dispensed preparations, etc., and to determine the source and nature of any defect. The range of products to be controlled comprises raw materials, drugs and packaging materials, formulated products, surgical dressings and sutures, medicated cosmetics and toiletries, medicated veterinary preparations, dispensed medicine and equipment for which claims for sterility are made. In the opinion of the Committee the functional testing of appliances is outside the scopo of this quality control scheme. Inspectors must be empowered to sample at any stage of production or formulation and to sample the finished product at any point between the manufacturer and tho consumer. By using proper control records, as stipulated, any defect that is revealed can be traced to its source. Where adequate records by manufacturers and importers exist, and are available for inspection, the extent of sampling may be reduced.

\section{Sampling Techniques}

Where a sample can be divided into replicate portions, it should be divided into three by tho inspector in the presence of a responsible person. One portion should be handed to the person from whom the samplo was obtained and the remaining samples taken away by the inspector. Of these two samples, one would be the subject of examination by the official analyst and the other would be retained as reference sample for independent testing should this be necessary. It is essential that each sample should be sealed, and clearly identifiable. The present sampling technique that is operated under the Food and Drugs Act would be applicable to general sampling under this scheme. For dispensed medicines, the sampling procedure detailed in Part 1 of the Seventh Schedule of the Food and Drugs Act, 1955, would possibly be suitep after the preliminary procedure specified under the Ministry of Health E.C.L. 7/61 Appendix 1, para. $6(a)$. Informal sampling for the purposes of obtaining general information is not precluded from the scheme.

Raw materials (chemical and packaging materials). Evidence on the quality of raw materials (and the packaging materials) could be obtained from the inspection of manufacturers' control records. Samples will be taken where, in the opinion of the inspector, doubts as to quality exist. In this connexion the use of such terms as British Pharmacopoia (B.P.), British Pharmaceutical Codex (B.P.C.), etc., demands complete compliance with the official monograph.

Formulated products (medical, veterinary or cosmetic). The routine sampling of manufacturers' stocks should be unnecessary where inspection of the internal control records indicates proper supervision and regular control. Where little or no analytical control is exercised, consultant-analyst certificates would give an indication of the extent to which products might need further examination.

An indication of product stability is of importance and attention will need to be directed to an expiry date to be applied to those products for which prolonged storage is undesirable.

Wholesalers' stocks. Probably only a few samples will noed to bo taken from the wholesalers' stocks, although the inspectors will have to ensure that the conditions of storage are satisfactory.

Importers' stocks. Importers of bulk drugs and formulated products should provide adequate information on: (a) specification of the raw materials used; (b) details of product manufacture; (c) details of product specification and control directions; $(d)$ product stability; $(e)$ intended procedure for distribution of stocks. Importers must supply samples on request. All imports should be submitted to some form of control as early as possiblo and each batch of each product must have an acceptable certificate of analysis. It is envisaged that protocols of analysis from the consignors might be permitted, but the presentation of such documents does not preclude any sampling that might be considered desirable. The issue of a certificate to distribute would generally involve an examination by a consultant in Britain, registered as competent in the analysis of medicated products and pharmaceuticals. Holders of the joint Pharmaceutical Society and Royal Institute of Chemistry Diploma in Pharmaceutical Analysis are considered to satisfy this requirement.

Dispensed products. The present sampling of dispensed medicines under the National Health Service Acts is felt to be inadequate both in scope and manner. All dispensaries, whether under medical, pharmaceutical, dental or veterinary direction, should be subject to some form of control. The techniques of sampling might usefully form the basis of discussions with representatives of the professions concerned. It is proposed that the inspector be authorized to take as a sample any medicine or form of treatment, including proprietary preparations, awaiting collection for a patient (human or animal). It is implicit in this scheme that the inspector be provided with a copy of the relevant prescription. Quantities, for example, of 
tablets, supplied against a proscription could be checked on the spot by the inspector.

Retailers (pharmacies, listed sellers, drug stores and retail suppliers of medicinal products). It is expected that, as at present under the Food and Drugs Act, most samples will continue to be taken from retail establishments. It would be convenient to use the proposed scheme to exercise enforcement of Section 2 of the Pharmacy and Medicines Act, 1944, or the appropriate section of a new Consolidated Drugs Act. Pharmacists, by virtue of their professional training, will have knowledge of drug deterioration, but other retailers, having little or no experience of the problems, can unwittingly subject medicated products to storage and exposure conditions that are quite unsuitable; the use of batch identification codes is important in tracing any errors. A special example of unsatisfactory storage is the vending machine which may be exposed to a wide range of climatic conditions.

\section{Sample Records}

Bulk drugs and formulated products from U.K. manufacturers. A comprehensive quality control system can only be operated in a manufacturing unit where an efficient internal control system exists. While it is not part of the Committee's responsibility to define what system should be adopted, certain features are considered to be essential if the scheme is to work to the advantage of both the manufacturer and the public. For example, adequate specifications and control methods for both raw materials and finished products are fundamental. Manufacturers should investigate the stability of their products, and keep adequate records available for inspection; inspectors must have power to examine such records. As an interim measure only-and for such time as may be determined by the Controlling Authoritythere may be some relaxation in respect of stability records, but manufacturers are urged to take serious note of the recommendation.

Supplies from importers. In tre absence of satisfactory technical information submitted by the consignors or by the consignee's consultant analyst imports need to be sampled. Information will bo required on: $(a)$ the raw materials used; $(b)$ specifications and control methods for the formulated products; (c) stability.

Reimbursement for samples taken. A scheme will have to bə dəvoloped whereby reimbursement can be made for samples taken for examination.

\section{ADMINISTRATION}

The Committee does not propose to specify the form of the Controlling Authority, which would undoubtedly have wider responsibilities than quality control. While the Minister of Health may have governmental responsibility, the executive functions should be carried out by an independent body having the necessary legal powers. This body should be given the entire responsibility for the quality control of drugs.

\section{Executive Organization}

In the opinion of the Committee, the Pharmaceutical Society of Great Britain would be an appropriate 'Executive Organization'. The Society already has enforcement duties under existing Pharmacy Acts and its inspectors have considerable experience of conditions in rotail pharmacy.

\section{Advisory Committee}

An advisory Committee-working in a voluntary capacity and including experienced representatives of the pharmaceutical industry-should be instituted to make recommendations on 'special cases' that may arise during the operation of any quality control programme, to advise on matters concerned with premises, registration, the issue of licences, etc., and to advise on general policy.

\section{Directorate}

To achieve effective quality control, a 'Directorate of Drug Testing' should be established. 'The Directorate would have the necessary powers of entry, inspection and sampling, and its own laboratory facilities. The directorin-charge, who should have appropriate technical qualifications, would be required to administer the scheme as a whole, and would be concerned with the day-to-day administration, inspection and sampling and with the analytical services. He should be directly responsible to the Executive Organization for all the activities of his department. The activities of inspectors and analysts involved in the control programme should be the responsibility of the director.

\section{Inspectors}

Inspectors should preferably hold a pharmaceutical qualification, but this would not preclude the appointment of other suitably qualified persons for specialist duties.

Qualifications. Inspectors must be trained in the techniques of sampling. Practical experience of manufacturing processes would be an advantage, as this would enable inspectors to act in an advisory capacity in matters related to drug control.

Functions of inspectors. The functions of inspectors will include: (a) inspection of premises of organizations seeking registration; (b) inspection on a routine basis of factories, warehouses, wholesalers' storerooms, hospital manufacturing and storage areas, dispensaries (medical, pharmaceutical, dental and voterinary), drug retailers' premises, clinies; (c) routine examination of control records of manufacturers; (d) routine examination of data sheets on importations; (e) the taking of samples and carrying out of local checks.

Manufacturers' analysts as inspectors. In other contexts manufacturers' analysts, under the supervision of the official inspectors, have been appointed as inspectors of their own organizations. In the proposed scheme this principle merits consideration.

\section{Laboratory Services}

A central laboratory will be required to carry out the analysis of samples submitted by the inspectors. Regional laboratories which will handle routine work may be needed since uniformity of interpretation of analytical results and of control is essential; the regional laboratories must be placed under the authority of the Central Laboratory. As an interim measure, until the establishment is at the requisite level, use of other laboratories, for example, those of public analysts and analysts holding appointments under the National Health Service Acts, might be considered. The authority of the director will, however, be paramount even where public analysts, who may be called on to sample over-the-counter sales, are concerned. The Laboratory of the Government Chemist should be used as a reference laboratory in cases of dispute.

Staffing (personnel). It is vital to the whole programme of a quality control scheme to establish confidence in the control exercised by the Central Laboratory. For this reason the staff must be of the highest calibre since it will be called on to conduct intricate analytical procedures and to undertake such analytical research as may be necessary to resolve problems. The senior members of the staff will be expected to advise the director on scientific and technical matters relating to the scheme. They would further be expected to participate on 
professional committees and collaborate on investiga tional work, possibly at international level.

Notes: (1) Since the testing of dressings requires special techniques, use should be made of established organiza. tions, for example, the Manchester Chamber of Commerce Testing Houso and Laboratory. (2) Specialized testing of materials by bioassay techniques will involve the co-operation of established organizations capable of making such tests.

\section{LEGISLATION}

It is not the purpose of this Committee to indicate in detail what legislation is involved, but it directs attention to the following matters. Consolidating legislation would have to be introduced to correlate and extend the existing legislation under the Pharmacy and Poisons Act, 1933, the Food and Drugs Act, 1955, the National Health Service Acts, the Pharmacy Act, 1954, and to provide the powers necessary to permit the Executive Organization to conduct its affairs in an efficient and responsible manner.

Right of entry and inspection. The inspectors must be given the necessary powers to carry out their duties properly both as regards sampling and the inspection of premises and records.

Test results. A procedure must be developed whereby information on the results of the tests are transmitted to the source from which the sample was obtained.

Sanctions. In addition to the usual legal penalties the following sanctions might be applied: $(a)$ withdrawal of licence; $(b)$ removal of name from approved list of supervisory staff; (c) stock recall, impounding or destruction.

Appeals. There must be included some means of appeal against decisions of the inspectors or the director.

\section{FINANCIAL}

Whereas a detailed consideration of the financial aspects of the scheme is beyond the terms of reference of the Committee, attention is directed to the following points :

Expenditure. (1) Administrative expense of Executive Organization. (2) Administrative expense of Directorate and Inspectorate, including laboratory services. (3) Fees to outside analysts (for example, analysts responsible for bio-assays, public analysts, National Health Service analysts, Manchester Chamber of Commerce Testing House).
Income. (1) From registration and licensing fees (except disponsing areas). (2) From the Treasury.

\section{INTERPRETATION}

A drug (or pharmaceutical preparation) is any chemical or natural product or mixture of substances, including natural products, sold, offered for sale or represented for use in: (a) the diagnosis, treatment, mitigation or prevention of disease, abnormal physical state or the symptoms thereof in man or animal; (b) restoring, correcting or modifying organic functions in man or animal.

Drug in bulk. A chemical or natural product stored in bulk quantity intended directly for use in the manufacture of medicinal products.

Frormulated product. A drug or mixture of drugs suitably prepared for administration as a medicine. A single chemical substance in small quantity, pre-packed for distribution.

Pharmaceutical specialty. A simple or compound drug ready for use, available under a special trade designation or in some characteristic form and containing one or more drugs which may or may not have official (that is, B.P., B.P.C., B.Vet.C.) recognition.

Proprietary preparation. A pharmaceutical specialty. Surgical dressings, surgical sutures. Materials for application to wounds or lesions for therapeutic use or for their protection.

Dispensed medicine. Medicine dispensed for an individual patient in accordance with a prescription.

Medicated cosmetic or toilet article. A toilet article for external use on any part of the body, whether in liquid, solid or any other form and medicated so as to bring it within the requirements of the Pharmacy and Medicines Act, 1941 .

\section{THE SCIENCE COMMITTEE (PHARMACEUTICAL ANALYSIS)}

The Science Committee (Pharmaceutical Analysis) of the Department of Pharmaceutical Sciences consists of: Dr. D. C. Garratt (chairman), Mr. J. Allen, Dr. A. L. Glenn, Mr. C. A. Johnson, Mr. E. I. Johnson, Dr. R. F. Milton, Dr. H. D. C. Rapson, Mr. S. G. E. Stevens and Mr. G. Sykes. Not all members are pharmacists, but all in their day-to-day activities are intimately concerned with the quality of pharmaceutical materials; some have had experience of drug testing under the present restricted schemes.

\section{THE FISHERY LIMITS BILL}

\begin{abstract}
7 HE Fishory Limits Bill, which received its second reading in the House of Commons on June 15, establishes the fishery régime in British waters for which the Fisheries Convention resulting from the fisheries conference some months ago provides. As the Minister of Agriculture, Fisheries and Food, Mr. C. Soames, explained in moving the second reading, the Convention, which has since been signed by twelve countries including the United Kingdom, allows the coastal State a twelve-mile fishery zone measured from base-lines, and within this zone the State has power to regulate the fisheries. In the inner six miles the fishing is rescrved for the fishermen of the coastal State, subject to a short transitional period for foreign fishermen who have traditionally fished within it. In the outer six miles the fishing is in principle reserved for fishermen of the coastal State and other parties to the
\end{abstract}

Convention who have habitually fished in that area. In this way such foreign fishermen will be restricted to the stocks and grounds which they have already fished.

Mr. Soames emphasized that while Britain had consistently favoured the doctrine of narrow limits, the Government had concluded that some extension of limits could no longer be denied to Britain's fishermen. The Government's sole motive had been to secure more scope for Britain's fishermen in Britain's coastal waters. As regards conservation, the Government considered that the proper way to conserve fish stocks was by international action equitable to all in the conservation com. missions which had been set up and in whose work Britain played a leading part. Mr. Soames said that there were some two or three countries which were not parties to the Convention but had some interest in the fisheries around 